\title{
En kvinne i 90-årene med akutt peritonitt
}

\author{
En kvinne i 90-årene ble innlagt med akutte magesmerter og kliniske \\ tegn på diffus peritonitt. Hun hadde en rekke andre sykdommer og \\ brukte medikamenter for dette. Utredningen viste en uvanlig årsak \\ til akutt peritonitt, der tablettbruken spilte en viktig rolle.
}

En kvinne i 90-årene kom til sykehuset med akutte magesmerter. Hun var nylig blitt utskrevet etter å ha blitt behandlet for akutt alvorlig kolecystitt med intravenøs antibiotika og perkutan galleblæredrenasje. Hun brukte en rekke medikamenter for andre sykdommer, i tillegg til perorale antibiotika og analgetika etter siste innleggelse. Hun hadde nedsatt syn og brukte tannproteser. Ved innkomst var hun våken og orientert, med noe redusert allmenntilstand og anga smerter diffust $i$ abdomen. Hun hadde lett feber $\left(38,3^{\circ} \mathrm{C}\right.$ ), lett takykardi (regelmessig puls $83 \mathrm{slag} /$ minutt), lett redusert oksygenmetning på romluft (89\%) og normalt blodtrykk $(151 / 83 \mathrm{~mm} \mathrm{Hg})$. Ved klinisk undersøkelse av abdomen var hun stram ved palpasjon og generelt trykk-og slippøm.

Sykehistorie og klinisk undersøkelse tydet på en akutt sykdom i bukhulen med peritonitt. Dette ga umiddelbart mistanke om inflammasjon eller perforasjon av et hulorgan i buken. En slik tilstand krever ofte akutt operasjon. Før en eventuell operasjon må man utelukke andre tilstander som kan gi et liknende klinisk bilde, men som ikke skal opereres: akutt hjerteinfarkt, basal pneumoni, basal lungeemboli, nyrestein og ureterstein, og enkelte sykdommer i bukhulen der akutt intervensjon oftest ikke er nødvendig: akutt pankreatitt, akutt kolecystitt og akutt ukomplisert divertikulitt. Man må også vurdere å undersøke for vaskulære årsaker til akutte magesmerter: akutt tromboemboli eller aneurismer/ruptur i viscerale kar.

Pasienten ble utredet med laboratorieprøver, EKG og CT abdomen med intravenøs kontrast. Laboratorieverdiene ved innkomst viste forhøyede inflammasjonsprøver, ellers upåfallende verdier: $H b$ 11,5 g/l (11,4-15,3 $\mathrm{g} / \mathrm{l})$, leukocytter $19,5 \cdot 10^{9} \mathrm{l}\left(3,5-8,8 \cdot 10^{9} \mathrm{l}\right)$, CRP $210 \mathrm{mg} / \mathrm{l} \quad$ (< $5 \mathrm{mg} / \mathrm{l}), \quad \mathrm{Na} 139 \mathrm{mmol} / \mathrm{l}$ (137- $145 \mathrm{mmol} / \mathrm{l}), \quad K 4,5 \mathrm{mmol} / \mathrm{l} \quad(3,6-5,0$ $\mathrm{mmol} / \mathrm{ll})$, kreatinin $87 \mu \mathrm{mol} / \mathrm{l}(56-110 \mu \mathrm{mol} / \mathrm{l})$, amylase $21 \mathrm{U} / \mathrm{l} \quad(10-60 \mathrm{U} / \mathrm{l}$, bilirubin 18 $\mu \mathrm{mol} / \mathrm{l} \quad(<25 \mu \mathrm{mol} / \mathrm{ll})$, alaninaminotransferase (ALAT) $22 \mathrm{U} / \mathrm{l}(10-45 \mathrm{U} / \mathrm{l})$, alkalisk fosfatase (ALP) $82 \mathrm{U} / \mathrm{l}$ (35-105 U/l). EKG viste sinusrytme uten iskemitegn. CT abdomen med kontrast viste normale basale lunge- avsnitt. I abdomen så man tegn til lokale inflammatoriske forandringer $i$ tynntarm med luft utenfor tarmvegg i relasjon til et fremmedlegeme i tarmlumen (fig 1).

Laboratorieprøvene støttet mistanken om en inflammasjon. Med normale hemoglobinverdier var en større blødning lite sannsynlig. Normale funn ved EKG utelukket akutt hjerteinfarkt. Klinisk hadde pasienten diffus peritonitt, i seg selv en klassisk operasjonsindikasjon. I dag gjøres likevel oftest CT abdomen hos sirkulatorisk stabile pasienter før behandling. CT, helst med intravenøs kontrast, er nå førstevalg ved radiologisk utredning av akutte magesmerter og har erstattet røntgen oversikt abdomen. Dersom pasienten har forhøyede kreatininverdier, må man veie risikoen for kontrastindusert forverring av nyresvikt mot tilleggsgevinsten som intravenøs kontrast gir. Eventuelt kan man utføre CT uten kontrast. Oppvæsking før undersøkelsen kan eventuelt redusere risikoen for kontrastindusert nyresvikt. $\mathrm{CT}$ er i dag en tilgjengelig og rask undersøkelse og gir ofte klinikeren en presis diagnose og mulighet til å målrette behandlingen. Hos denne pasienten ga kliniske funn og CT-undersøkelse diagnosen og operasjonsindikasjonen.

Pasienten ble operert med akutt laparotomi, der man fant et skarpt hjørne på folien til en blisterpakning stikkende ut av tarmveggen (fig 2). Dette ble behandlet med tarmreseksjon og primær anastomose. Inni tarmen fant vi en blisterpakning med tablett (fig 3). Denne hadde beveget seg nedover tarmen og laget langsgående ulcerasjoner, før den til slutt laget en tynntarmsperforasjon. Det postoperative forløpet etter tarmreseksjonen var ukomplisert. Hun fikk imidlertid påvist steiner i choledochus, fjernet ved endoskopisk retrograd kolangiopankreatikografi (ERCP) $i$ to seanser. Dette forlenget sykehusoppholdet noe, men 14 dager etter operasjonen kunne hun skrives ut $i$ velbefnnende.

\section{Diskusjon}

De aller fleste mindre fremmedlegemer som spises vil passere gastrointestinalkanalen uten at det oppstår problemer. Tarmskader

\author{
Muhammad Shafique \\ Lars Martin Rekkedal \\ Mathilde Berg \\ Gastrokirurgisk avdeling \\ Erik Haavardsholm* \\ Bildediagnostisk avdeling \\ Akershus universitetssykehus

\section{Ola Røkke} \\ Gastrokirurgisk avdeling \\ Akershus universitetssykehus \\ og \\ Medisinsk fakultet \\ Universitetet i Oslo
}

* Nåværende adresse:
Radiologisk avdeling
Diakonhjemmet sykehus

> Se lederartikkel side 2235 
kan oppstå når fremmedlegemet er spisst eller ufordøyelig, som for eksempel kyllingbein, fiskebein, tannpirkere, nåler eller små kantete kakedekorasjoner (1-3) som kan forårsake blødning, ulcerasjon, fisteldanning eller perforasjon. Tarmkomplikasjoner pga. tablettemballasje er uvanlig, men er tidligere beskrevet (4). Perforasjon av tarm skjer ofte i terminale ileum, noen centimetre før iliocøkalklaffen. Perforasjoner kan også skje andre steder i tynntarm, coekum, colon sigmoideum eller i duodenum (5-8). Barn og eldre med redusert syn og/eller andre alvorlige sykdommer er mer utsatt for dette.

Tabletter selges ofte i esker, der tablettene ligger i plastkopper støpt i et brett dekket av aluminiumsfolie (blisterpakninger). Meningen er å trykke tablettene ut gjennom aluminiumsfolien før man spiser dem. Tidvis er det perforasjoner mellom blisterenhetene slik at det skal være enkelt å ta ut en dose/ tablett mens den fremdeles er beskyttet. Mange brett har ikke disse perforasjonene og må eventuelt klippes fra brettet om man ønsker enheter med én dose. Vår pasient hadde svelget én enkelt tablett i sin blisterpakning. Blisterpakningen var brukket eller klippet løs på brettet og besto av en kvadratisk fast gjenstand med svært spisse hjørner, som hun fikk utlevert og inntok sammen

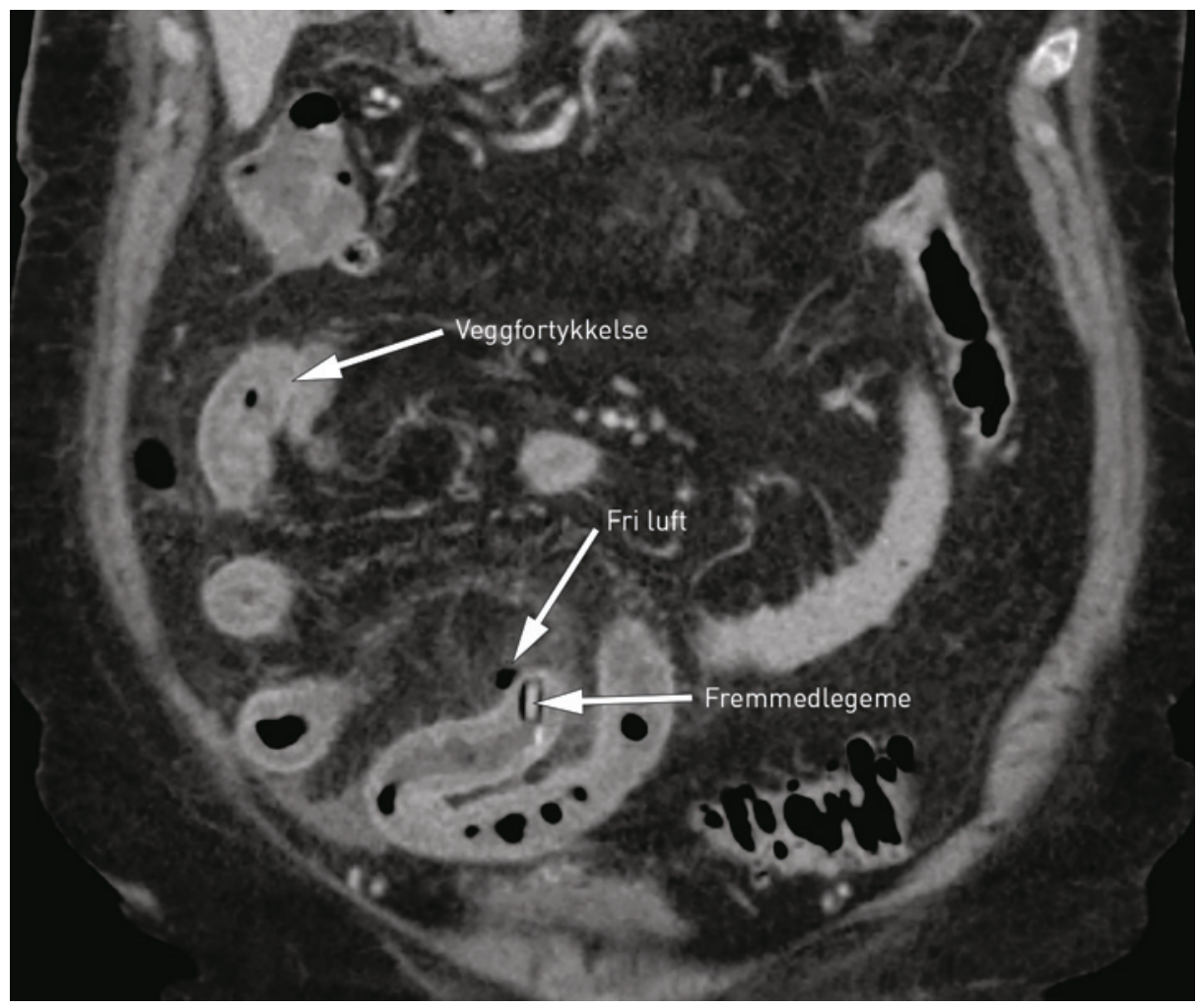

Figur 1 CT-abdomen viser perforasjon av tynntarm ved fremmedlegemet (tablett i blisterpakning) samt veggfortykkelse/ødem i tarmvegg oralt for fremmedlegemet

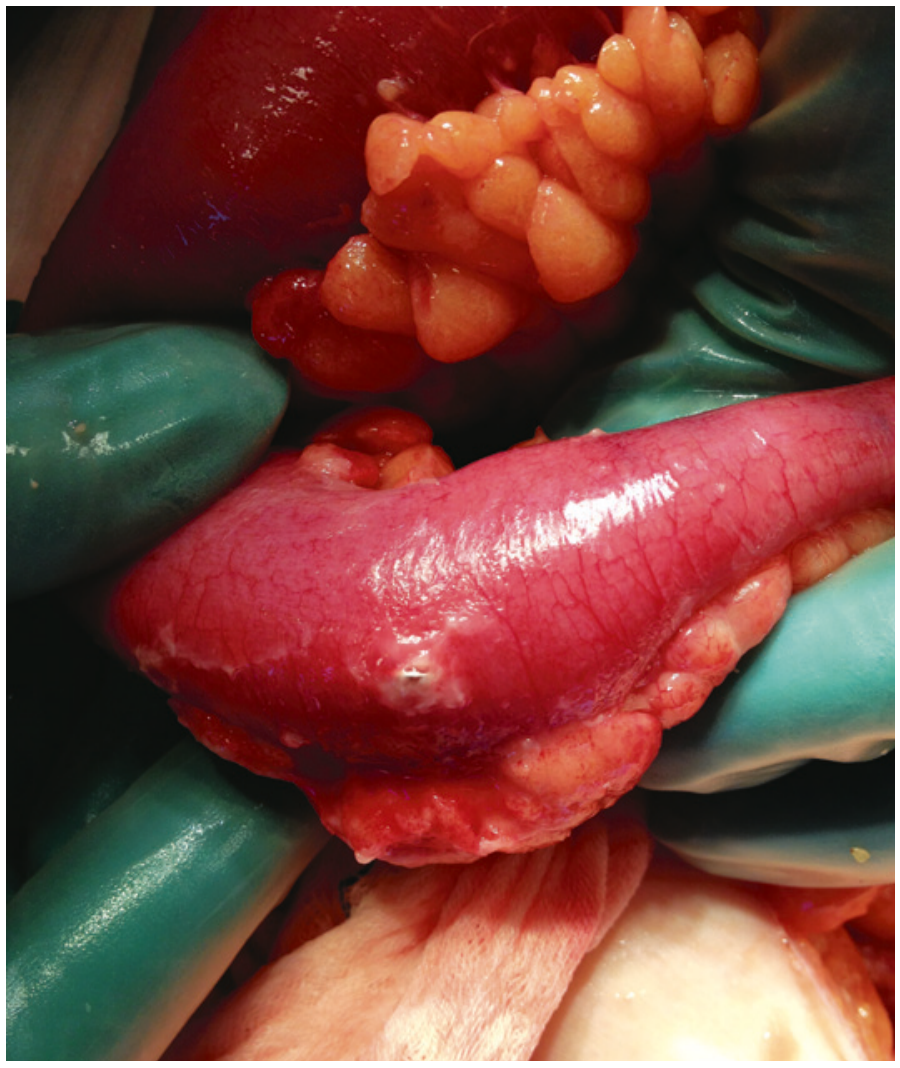

Figur 2 Foto av tynntarm med blisterpakning stikkende ut

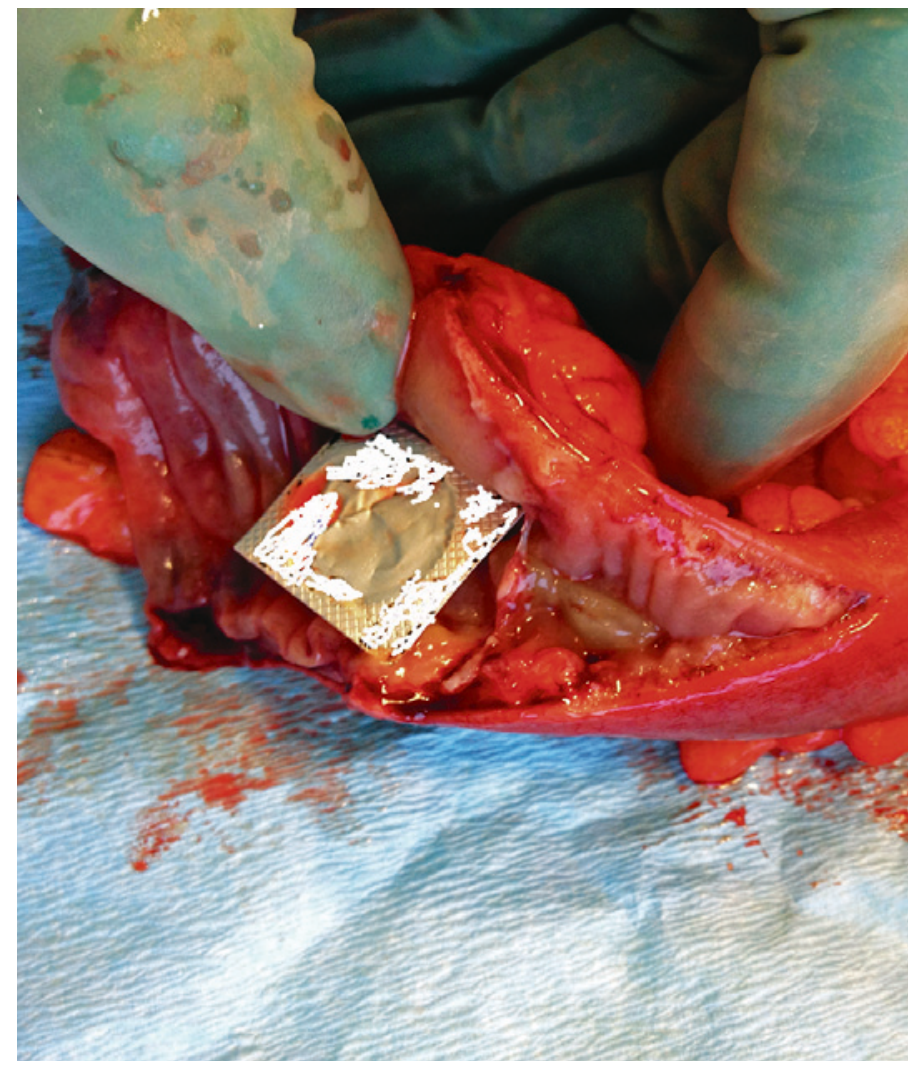

Figur 3 Foto av tablett i blisterpakning (retusjert for å unngå identifikasjon av varemerke) i åpnet tynntarm, med langstrakt traumatisk ulcerasjon og veggfortykkelse 
med sine andre faste medisiner. Det at hun nettopp hadde gjennomgått annen sykdom og var svekket av dette samt hadde redusert syn og redusert sensibilitet i munnhule pga. tannproteser bidro til at hun ikke registrerte at tabletten fremdeles lå i blisterpakningen og dermed svelget den hel.

Klinisk er det ikke mulig å skille tynntarmsperforasjoner fra perforasjoner andre steder i gastrointestinalkanalen. CT abdomen med kontrast er den beste undersøkelsen for raskt å påvise årsaken til akutte tilstander i buken, i dette tilfellet et fremmedlegeme, og å lokalisere tarmperforasjonen (8). Laparotomi med tarmreseksjon er nødvendig. Laparoskopisk intervensjon kan være alternativ metode.

I årene som kommer vil det bli stadig flere eldre og syke pasienter som bruker tabletter. En måte å forebygge tilstanden på er å benytte andre former for enkeltpakning av tabletter enn blister.

Pasienten har gitt samtykke til at artikkelen blir publisert.

\section{Muhammad Shafique (f. 1975)}

er spesialist i generell kirurgi.

Forfatter har fylt ut ICMJE-skjemaet og oppgir

ingen interessekonflikter.

Lars Martin Rekkedal (f. 1977)

er overlege.

Forfatter har fylt ut ICMJE-skjemaet og oppgir ingen interessekonflikter.

\section{Mathilde Berg (f. 1974)}

er spesialist i generell kirurgi.

Forfatter har fylt ut ICMJE-skjemaet og oppgir ingen interessekonflikter.

\section{Erik Haavardsholm (f. 1982)}

er lege i spesialisering.

Forfatter har fylt ut ICMJE-skjemaet og oppgir

ingen interessekonflikter.

\section{Ola Røkke (f. 1953)}

er spesialist i generell kirurgi og i gastroenterologisk kirurgi og overlege.

Forfatter har fylt ut ICMJE-skjemaet og oppgir ingen interessekonflikter.

\section{Litteratur}

1. Singh RP, Gardner JA. Perforation of the sigmoid colon by swallowed chicken bone: case reports and review of literature. Int Surg 1981; 66: 181-3.

2. Kiff ES, Hulton N. Small bowel perforation due to a Christmas cake decoration. Br Med J (Clin Res Ed) 1983; 287: 1923-4.

3. Bhatia R, Deane AJ, Landham P et al. An unusual case of bowel perforation due to fish fin ingestion. Int J Clin Pract 2006; 60: 229-31.

4. Crowley LV, Bretzke ML. Bowel perforation from ingested unit dose blister-pak. Am J Gastroenterol 1988; 83: 1011-2.

5. Norstein J, Krajci P, Bergan A et al. Intestinal perforation after ingestion of a blister-wrapped tablet. Lancet 1995; 346: 1308.

6. Fulford S, Tooley AH. Intestinal perforation after ingestion of a blister-wrapped tablet. Lancet 1996 347: $128-9$

7. Fierens K, Van Outryve L, Kint M. Bowel perforation from ingested blister-pack. Acta Chir Belg 2007: 107: $564-5$.

8. Coulier B, Tancredi MH, Ramboux A. Spiral CT and multidetector-row CT diagnosis of perforation of the small intestine caused by ingested foreign bodies. Eur Radiol 2004: 14: 1918-25.

Mottatt 4.4. 2014, første revisjon innsendt 8.7. 2014, godkjent 8.9. 2014. Redaktør: Sigurd Høye. 